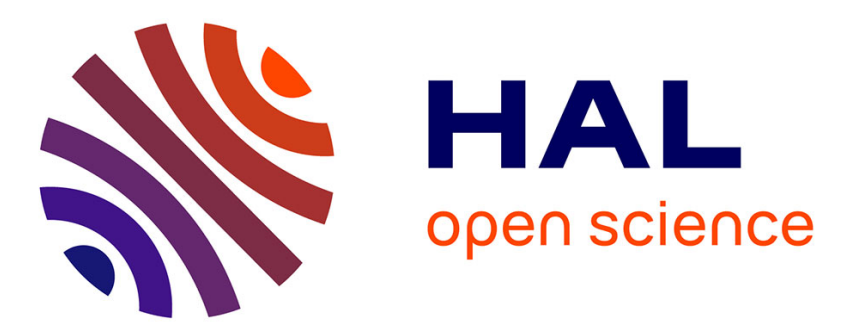

\title{
Simple and reliable models of density decrease with dominant height growth for even-aged natural stands and plantations
}

Tatiana Stankova, Ulises Diéguez-Aranda

\section{- To cite this version:}

Tatiana Stankova, Ulises Diéguez-Aranda. Simple and reliable models of density decrease with dominant height growth for even-aged natural stands and plantations. Annals of Forest Science, 2013, 70 (6), pp.621-630. 10.1007/s13595-013-0303-y . hal-01201506

\section{HAL Id: hal-01201506 \\ https://hal.science/hal-01201506}

Submitted on 17 Sep 2015

HAL is a multi-disciplinary open access archive for the deposit and dissemination of scientific research documents, whether they are published or not. The documents may come from teaching and research institutions in France or abroad, or from public or private research centers.
L'archive ouverte pluridisciplinaire HAL, est destinée au dépôt et à la diffusion de documents scientifiques de niveau recherche, publiés ou non, émanant des établissements d'enseignement et de recherche français ou étrangers, des laboratoires publics ou privés. 


\title{
Simple and reliable models of density decrease with dominant height growth for even-aged natural stands and plantations
}

\author{
Tatiana V. Stankova $\cdot$ Ulises Diéguez-Aranda
}

Received: 28 September 2012 / Accepted: 22 May 2013 /Published online: 11 June 2013

(C) INRA and Springer-Verlag France 2013

\begin{abstract}
- Context Regular mortality (or self-thinning) is an integral part of woody plant dynamics, and the mortality model is one of the most important transition functions within dynamic growth models.

- Aims The main objectives of the present study were to derive one-step stand-level mortality models for estimating the reduction in stand density with stand dominant height growth and to examine the applicability of the models in predicting regular mortality trends in even-aged natural stands and plantations.

- Methods Four model formulations based on graphical examination of the main trends in the data and on defined desired properties of the selected mathematical functions were proposed and tested in algebraic difference equation form with two datasets from pine plantations and two datasets from natural broadleaved even-aged stands.

- Results The mortality patterns of three of the datasets were characterized by reverse sigmoid curves, while the forth dataset exhibited a reverse J-shaped trajectory. The models analyzed adequately represented the density decrease trends of the data through sets of polymorphic curves with multiple asymptotes.

- Conclusion The dominant height-dependent mortality equations provide a simple and reliable approach to modeling the regular density decrease trends and can be considered for
\end{abstract}

Handling Editor: Barry Alan Gardiner

Contribution of the co-authors Tatiana V. Stankova: data collection, models derivation, data analysis, and writing of the manuscript.

Ulises Diéguez-Aranda: data collection, scientific advice, supervision and corrections of the work, and coordination of the research project.

T. V. Stankova $\cdot$ U. Diéguez-Aranda

Department of Agroforestry Engineering,

University of Santiago de Compostela, Lugo, Spain

T. V. Stankova $(\square)$

Department of Forest Genetics, Physiology and Plantations,

Forest Research Institute of Bulgarian Academy of Sciences,

132 St. Kliment Ohridski Blvd, 1756 Sofia, Bulgaria

e-mail: tatianastankova@yahoo.com incorporation as a submodel within the framework of a dynamic Stand Density Management Diagram.

Keywords Competition-induced mortality $\cdot$ Stand-level models $\cdot$ Even-aged stands $\cdot$ Dominant height growth $\cdot$ Density Management Diagrams

\section{Introduction}

Competition-induced tree mortality is an important process in forest growth and yield, and it has been recognized as being difficult to model. Hawkes (2000) stated that mortality should be an integral part of any model of woody plant dynamics, while Álvarez-González et al. $(2004,2010)$ pointed out that the mortality model is one of the most important transition functions within the system of dynamic growth and yield models. Although numerous classifications of the approaches used to model regular (competition-induced) mortality have been proposed, here we consider categorization according to the modeling scale, i.e., individual-tree and stand-level mortality models. Survival of a tree is described by only two values (representing dead and live trees), and the mortality (or survival) probability is therefore modeled by a probabilistic approach involving cumulative distribution functions bounded between 0 and 1 . The logistic probability function is most widely used for this purpose (Palahí et al. 2003; Adame et al. 2010; CrecenteCampo et al. 2010), and different explanatory variables related to tree and stand growth, size, and vitality are used to predict the probability of tree death or survival (Eid and Øyen 2003; Collet and Moguedec 2007). Stand-level mortality models, on the other hand, express the rate of decrease in tree number per unit area and obtain the form of a functional relationship of tree number on the stand age, which is fitted by a mortality rate approach involving dynamic difference equation forms (Clutter et al. 1983). In addition to stand age, stand-level mortality functions can also include other explanatory variables such as 
site index (Álvarez-González et al. 2004; Diéguez-Aranda et al. 2005b) and some competition intensity measures, such as relative density index (Newton 2012a, b). The probabilistic approach can also be applied at the stand level, leading to classification of the stands into two categories: stands that have been subject to regular mortality for a certain period of time and stands that have not been subject to regular mortality. However, this approach is only considered in the first step in two-step (Woollons 1998; Eid and Øyen 2003; Álvarez-González et al. 2004; Diéguez-Aranda et al. 2005b) and three-step (Fridman and Ståhl 2001; García-Gonzalo et al. 2011) stand-level mortality models, which combine the probabilistic and the mortality rate approaches. The mortality rate approach is applied in the subsequent steps of these composite models, but only to the data from the stands where mortality occurred. Such complex multistage models have been developed to account for the high degree of variability at stand level and to overcome some difficulties related to fitting one-step mortality rate models: inclusion of the non self-thinned plots in the dataset is likely to cause convergence problems (Woollons 1998), whereas their omission might overestimate mortality rates (Álvarez-González et al. 2004; Eid and Øyen 2003). However, regardless of the degree of complexity, stand rate mortality models must possess several essential logical properties (Clutter et al. 1983): consistency, path invariance, and asymptotic zero limit of stocking density when time tends to infinity.

Stand Density Management Diagrams (SDMDs) are a type of a stand-level model primarily used to derive density control schedules by management objective and can be subdivided into (1) static SDMDs, which lack a temporal density decrease submodel and (2) dynamic SDMDs, which include submodel for density decrease in time (Newton 2009). Another specific aspect of this type of model is that it is usually presented in a graphical (diagrammatic) form, which is built in metrics and allows direct estimation of main stand-level variables (dominant height, quadratic mean diameter, number of trees and total stand volume per unit area, and stocking rate), if two of them are known or obtained in a field survey. The time dimension, which in its classical form is represented by stand age, is not expressed directly, but enters the diagram via the dominant height isolines, and can be estimated through established site-specific height-age curves. This explains why the density decrease submodel included in dynamic SDMDs usually requires supplementary information about stand age and/or site index (Castedo-Dorado et al. 2009; Newton 2012a, b), which is not directly obtainable from the diagram. Another approach in modeling the dynamic component of the SDMD is to express directly volume or biomass growth in time as a function of the decrease in density (Shibuya 1995; Hagihara 1998; Stankova and Shibuya 2007) in a set of natural thinning trajectories, thus bypassing the submodel of density decrease with time.
Woodall et al. (2005) indicate that knowledge of the age of a tree is not necessary for implementation of survival analyses and that any measurement unit that indicates changes in an individual's status between remeasurements may replace the traditional survival analysis variables of age and time. They considered breast-height diameter in their study, whereas Rennolls and Peace (1986) tested the top height in a mortality rate model that they themselves proposed (sensu Rennolls and Peace 1986).

In view of these notions about the variables that should be included in a mortality model, and considering direct incorporation of the density decrease submodel into the framework of the graphical SDMD, there is a need for mortality models based on a stand growth variable other than age. Therefore, the main objectives of the present investigation were as follows: (1) to derive stand-level mortality rate models to estimate the decrease in stand density with stand dominant height growth and (2) to examine the models in algebraic difference equation form with data from even-aged coniferous and broadleaved natural stands and plantations.

\section{Materials and methods}

\subsection{Datasets}

We used four datasets - two from coniferous plantations and two from natural even-aged broadleaved stands - to fit the proposed mortality models. Three of the datasets comprised measurements from permanent sample plots in radiata pine plantations (Pinus radiata D. Don.), natural stands of English oak (Quercus robur L.) and downy birch (Betula pubescens Ehrh.) located throughout Galicia (northwest Spain), and the fourth dataset was generated from measurements taken in Scots pine (Pinus sylvestris L.) plantations in Bulgaria. The plot size varied depending on stand density, so that each plot included a minimum of 30 trees and the plots were subjectively selected in order to cover the existing range of sites, densities, and growth stages of these stand types. Only plots that had not been thinned, or had been subjected to light thinning from below were included in the datasets. We used repeated measurements of stand density (expressed as number of trees per hectare) and dominant stand height (in meters) for model parameterization (Table 1).

The plots in radiata pine plantations, which were established below $900 \mathrm{~m}$ above sea level (asl), ranged from 625 to $1,200 \mathrm{~m}^{2}$ in size and were measured two or three times, at 1to 6-year intervals, between 1995 and 2005. The birch stand data were obtained from 52 permanent sample plots of size $200-1,000 \mathrm{~m}^{2}$, in the altitudinal range $277-1,370 \mathrm{~m}$ asl, and the plots were measured twice, at 7- to 10-year intervals, in the period 1997-2008. The third dataset was generated from 57 plots, of size $225-1,350 \mathrm{~m}^{2}$, established in oak stands at 
Table 1 Description of the datasets

\begin{tabular}{|c|c|c|c|c|c|c|c|c|c|c|}
\hline \multirow[t]{2}{*}{ Tree species } & \multirow{2}{*}{$\begin{array}{l}\text { Number of } \\
\text { sample plots }\end{array}$} & \multirow{2}{*}{$\begin{array}{l}\text { Total number of } \\
\text { measurements }\end{array}$} & \multicolumn{4}{|c|}{ Stand dominant height (m) } & \multicolumn{4}{|c|}{ Stand density (trees $\mathrm{ha}^{-1}$ ) } \\
\hline & & & Mean & $\begin{array}{l}\text { Standard } \\
\text { deviation }\end{array}$ & Min & Max & Mean & $\begin{array}{l}\text { Standard } \\
\text { deviation }\end{array}$ & Min & Max \\
\hline Downy birch & 52 & 104 & 16.8 & 3.7 & 7.4 & 24.5 & 1,527 & 965 & 350 & 5,600 \\
\hline English oak & 57 & 147 & 18.4 & 3.1 & 9.9 & 24.6 & 780 & 340 & 158 & 1,744 \\
\hline Radiata pine & 136 & 309 & 20.9 & 5.8 & 5.9 & 35.2 & 920 & 490 & 192 & 2,048 \\
\hline Scots pine & 46 & 129 & 17.0 & 5.5 & 6.4 & 32.5 & 2,124 & 1,639 & 393 & 8,640 \\
\hline
\end{tabular}

altitudes between 338 and $845 \mathrm{~m}$ asl; the plots were measured two or three times, at 3- to 9-year intervals, between 1999 and 2009. Total tree height of a sample including the dominant trees (the proportion of the 100 largest-diameter trees per hectare, depending on plot size) was measured to determine the dominant stand height. The data records for Scots pine plantations were taken in permanent sample plots of size $150-2,000 \mathrm{~m}^{2}$, which were located at altitudes of between 450 and 1,600 m asl and have been measured two to four times since the 1970s. These data were obtained from plots, which were used to develop growth and yield tables for Scots pine plantations (Krastanov et al. 1980) and were remeasured once at 2-year intervals, from remeasured twice experimental plots in Scots pine plantations against erosion (Marinov 2008), and from monumented plots established for inventory purposes and measured two to four times at 9-12 year intervals. We estimated the dominant height for the plots in this dataset from the experimental mean plot height, using the relationship established by Stankova et al. (2006).

\subsection{Derivation of the models}

The stand density decrease process is known to involve three main phases (Rennolls and Peace 1986; Shibuya 1995). The early phase, prior to the onset of the competition-induced mortality, is characterized by little or no reduction in tree number because the plants are small (relative to the available growth space), do not experience lack of life-supporting resources and do not compete for resources. In the second phase, the onset of which depends significantly on stand density, the trees undergo severe competition for light and nutrients, and the mortality rate is high. Intensive self-thinning slows down as growth decreases with advancing age, which leads to establishment of an equilibrium between the plant needs and resource availability (third phase). This understanding of the pattern of stand density decrease suggests a reverse sigmoid to reverse J-shaped trajectory of the tree number as a function of the growth stage; such trends in density reduction were distinguished in all datasets examined (e.g., as later shown in Fig. 2). Trends in the modeled variable, which are inversely proportional to the time, can be described in different ways.
One simple approach is through a power function of negative exponent:

$N=c_{0} H^{-b_{1}}$

where $N$ is stand density (trees per hectare), $H$ is dominant stand height (in meters), and $c_{0}$ and $b_{1}$ are positive model parameters. Parameter $c_{0}$ can be viewed as an asymptotic value of stand density at the initial growth stage, designated by stand height $H=1 \mathrm{~m}$ and can be considered a stand and site specific parameter.

Another way to describe diminishing with the time number of trees per unit area is through an inverse relationship. Such a relationship can be obtained by modifying the power function of M1 given in the form:

$N=\frac{1}{c_{0} H^{b_{1}}}$

We propose to assign a specific constant value to the exponent of $H$, e.g., $b_{1}=2$, while including a free term in the denominator of Eq. 1 to allow for model flexibility. The second density decrease model examined is formulated as follows:

$N=\frac{1}{c_{0} H^{2}+b_{1}}$

Unlike M1, model M2 has an inflection point and asymptotic value for the initial growth stage $(H=1 \mathrm{~m})$ equal to $1 /\left(c_{0}+b_{1}\right)$.

The time trajectory of tree number per unit area can also be accurately described by an exponential decrease function, such as the mortality model proposed by Hagihara (2000), which is defined in terms of biological time $\tau$ :

$N=\alpha \exp (-\mu \tau)=\exp \left(\ln a^{-} \mu \tau\right)$

where $\mu$ is a mortality rate parameter and $\alpha$ corresponds to the integration constant and presents the asymptotic value of the initial stand density. Under the assumption of a proportional mortality rate constant across all ages, site indices and 
stand densities (Clutter et al. 1983), parameter $\mu$ should be viewed as a global model parameter, but this is rather a simplification. Furthermore, providing that the natural thinning process begins earlier in highly stocked stands and that the stand density approaches an asymptotic nil value as time tends to infinity, regardless of the different tree numbers at the time of stand establishment, a steeper slope of the density decrease trajectory is inferred with the increase in initial density, i.e., $\mu \sim \alpha$. Consequently, Eq. 2 can be reformulated in the following manner:

$N=\exp \left(c_{0}-b_{1} c_{0} \tau\right)=\exp \left[c_{0}\left(1-b_{1} \tau\right)\right]$

where $c_{0}=\ln \alpha, \mu=b_{1} \ln \alpha=b_{1} c_{0}, \quad c_{0}$ is a stand-specific parameter $\left(c_{0}>1\right.$ given the logical expectation for $\left.\alpha>e\right)$ and $b_{1}$ is a global model parameter $\left(0<b_{1}<1\right)$. The term $1-b_{1} \tau$ of Eq. 3, which obtains positive values below 1 , assures that stand density decreases with the progress of time and approaches asymptotic zero limit as time tends to infinity, while the asymptotic initial density for the time of stand establishment obtains value of $\exp c_{0}$. The same logical properties of the density decrease model are provided, if this term is substituted by a reciprocal relationship, e.g., $1 /\left(b_{1}+\tau\right), b_{1}>0$. Indeed, diminishing with the time pattern of stand density is guaranteed, asymptotic value of $N=1$ (which is virtually equivalent to the nil asymptotic value) is approached when time becomes infinitely large, and asymptotic initial density equal to $\exp \left(c_{0} / b_{1}\right)$ is estimated for the time of stand establishment. The biological time $\tau$ is defined as an integrated value of the coefficient of growth $\lambda(\tau)$ with respect to physical time $t$ (sensu Hagihara 2000), which implicitly derives its adequate substitution by the dominant stand height $H$. With this reasoning, the next density decrease model is derived as:

$N=\exp \left(\frac{c_{0}}{b_{1}+H}\right)$

The trend of decreasing density with increasing height growth can be strengthened by raising the dominant stand height to a power, as follows:

$N=\exp \left(\frac{c_{0}}{b_{1}+H^{2}}\right)$

The four mortality models proposed and tested are shown in Table 2 in their integral and algebraic difference equation forms.

\subsection{Estimation method and goodness of fit statistics}

We fitted mortality models M1-M4 in algebraic difference equation form, using a similar method to the Base-Age Invariant
Table 2 Mortality models derived and examined in the present study

\begin{tabular}{lll}
\hline Model & Integral form & Algebraic difference equation form \\
\hline M1 & $N=\frac{c_{0}}{H^{b_{1}}}$ & $N_{2}=N_{1}\left(\frac{H_{1}}{H_{2}}\right)^{b_{1}}$ \\
M2 & $N=\frac{1}{c_{0} H^{2}+b_{1}}$ & $N_{2}=\left[\left(\frac{H_{2}}{H_{1}}\right)^{2}\left(N_{1}^{-1}-b_{1}\right)+b_{1}\right]^{-1}$ \\
M3 & $N=\exp \left(\frac{c_{0}}{b_{1}+H}\right)$ & $N_{2}=N_{1}^{\left(\frac{b_{1}+H_{1}}{b_{1}+H_{2}}\right)}$ \\
M4 & $N=\exp \left(\frac{c_{0}}{b_{1}+H^{2}}\right)$ & $N_{2}=N_{1}^{\left(\frac{b_{1}+H_{1}^{2}}{b_{1}+H_{2}^{2}}\right)}$
\end{tabular}

$b_{1}$ global model parameter; $c_{0}$ site-specific model parameter; $N, H$-stand density (trees per hectare) and dominant stand height (in meters) in integral equation form; $N_{i}, H_{i}$ stand density (trees per hectare) and dominant stand height (in meters) in the $i$ th point in time in the algebraic difference equation form

(BAI) dummy variable approach proposed by Cieszewski et al. (2000). The BAI methods consider that the response variable in the self-referencing equations plays an important role in estimating the site-specific parameters and that the data always contain measurement and environmental errors (both on the left and right hand sides of the model) that must be modeled explicitly (Cieszewski 2003). These methods exhibit invariance property of the parameter estimates by fitting the curve to the observed trend in the data instead of forcing the model through any given measurement, thus circumventing complications due to the different data structures. The BAI methods are proposed and developed to fit the site index models where dominant height is the dependent variable and stand age the independent variable (Cieszewski et al. 2000; Cieszewski 2003; Diéguez-Aranda et al. 2005a). The BAI dummy variable approach was adapted here for a model formulation in which stand height is the independent variable and stand density (number of trees) is the dependent variable; the approach is therefore a "Base-Height Invariant" (BHI) method.

Implementation of this method requires fitting the difference equations $N_{2}=f\left(N_{1}, H_{1}, H_{2}\right.$; Table 2, column 3$)$ in the form:

$N_{2}=f\left(\sum p_{i} Z_{i}, H_{b}, H_{2}\right)$

where $p_{i}$ are dummy variables of value 1 for plot $i$ and 0 otherwise, $H_{b}$ is base dominant height (corresponding to the base age in the original method) assigned to each plot and arbitrarily chosen from among the available dominant stand height values for the plot, and $Z_{i}$ is the plot value of density 
(trees per hectare) corresponding to $H_{b}$. In the BHI dummy variable method, measurements of the modeled variable, which in the base height-specific methods are strict predictors of the dependent variable, provide only initial values for fast convergence and are fitted as plot-specific parameters; they are therefore allowed to vary along with the predicted variables. The important outcomes of this fit are not the particular plot (or stand) specific parameter estimates, but the estimates of the global model parameters (e.g., $b_{1}$ ), which are invariant, irrespective of the chosen base dominant heights, as ensured by the BHI method.

The assumption of independent errors is very likely to be violated in estimating regression equations with data from repeated measurements of permanent sample plots. Furthermore, the combined time-series cross-sectional nature of the remeasurement data contributes to manifesting heterogeneous variances. In the presence of autocorrelated and/or heteroscedastic errors, ordinary least squares estimation still produces unbiased parameter estimates, but the error variances are inflated and might lead to erroneous conclusions about the significance of the regression model and its parameters. Tests for the presence of serial correlation might be inadequate, because forest stand data do not usually constitute a single series (e.g., the present study), but rather a multiplicity of concurrent, relatively short time series (sensu Gregoire 1987). In the models examined in the present study, we used dominant height expressed as non-integer numbers, rather than the time variable (years), which further obscures development of continuous-time autoregressive error structure, as suggested in studies by Gregoire et al. (1995) and Diéguez-Aranda et al. (2005a). Heteroscedasticity and autocorrelation consistent (HAC) estimation of covariance matrices has been proposed to deal with conditional heteroscedasticity and serial correlation of regression disturbances of unknown form (Andrews 1989). Therefore, we applied HAC estimation of the standard errors, by using the generalized method of moments (GMM) with the Newey-West covariance matrix estimator (Andrews 1989), to obtain an unbiased evaluation of the regressions and their parameters. We also examined the HAC estimation based on the quadratic spectral kernel, which is recommended as the optimal HAC estimator (Andrews 1989), but found that it produced almost identical results to those produced by the classical HAC estimator of Newey-West, based on the Bartlett kernel. Therefore, we finally used the classical HAC estimator.

Model comparison was preceded by examination of the adequacy of the biological properties of the fitted functions. Models that failed to comply with the requirement for logical behavior of the mortality curve (i.e., if $H_{2}>H_{1}$ then $N_{2}<N_{1}$ ) for any of the plots were excluded from further analysis. We selected the most appropriate model on the basis of the adjusted coefficient of determination $\left(R_{\text {adj }}^{2}\right)$, the root mean square error (RMSE), the absolute (Bias (abs.)) and the relative (Bias (relat.)) biases:

$R_{\text {adj }}^{2}=1-\frac{(n-1) \sum_{i=1}^{n}\left(N_{i}-\widehat{N}_{i}\right)^{2}}{(n-k) \sum_{i=1}^{n}\left(N_{i}-\bar{N}\right)^{2}}$

$\mathrm{RMSE}=\sqrt{\frac{\sum_{i=1}^{n}\left(N_{\mathrm{i}}-\widehat{N}_{i}\right)^{2}}{n}}$

$\operatorname{Bias}($ abs. $)=\frac{\sum_{i=1}^{n}\left(N_{i}-\widehat{N}_{i}\right)}{n}$

$\operatorname{Bias}($ relat. $)=\frac{\sum_{i=1}^{n}\left(\frac{N_{i}-\widehat{N}_{i}}{N_{i}}\right)}{n} 100 \%$

where $N_{i}$ and $\widehat{N}_{i}$ are observed and predicted stand densities on the $i$ th plot, $n$ is the sample size, and $k$ is the number of model parameters.

We further assessed the predictive abilities of the selected mortality models by considering the $95 \%$ confidence $(\mathrm{CI})$, prediction $(\mathrm{PI})$, and tolerance $(\mathrm{TI})$ error intervals and by examining plots of observed against predicted values:

$95 \% C I=B \pm S t_{0.975} / n^{1 / 2}$

$95 \% P I=B \pm S t_{0.975}(1+1 / n)^{1 / 2}$

$95 \% T I=B \pm S g(1-g, n, 1-a)$ for $1-g=1-a=0.95$

where $B$ is the bias (Bias (abs.) or Bias (relat.)), $S$ is the standard deviation of the errors, $t_{0.975}$ is the 0.975 quantile of the $t$ distribution with $n-1$ degrees of freedom, the function $g(1-\gamma, n, 1-\alpha)$ is the tolerance factor tabulated for specified values of $n, \alpha$, and $\gamma$ and provides that the estimated interval will contain at least $(1-\gamma) 100 \%$ of the future error distribution with probability $(1-\alpha)$. We checked the normality of the residuals distribution prior to the error intervals estimation by visual examination of the histogram and the quantile-quantile plot $(Q-Q$ plot), and by evaluation of the skewness and kurtosis of the distribution. 


\section{Results}

Model M2 failed the requirement for biologically logical behavior for some of the plots in radiata pine plantations, and it was therefore excluded from further comparisons (Table 3). Model M4 performed better than the other tested models regarding the mortality trends in radiata pine plantations, birch, and oak stands (Table 3), and it proved high goodness-of-fit in the regressions, as shown by the estimated $R^{2}$ adj values, RMSE, and biases (Table 3), and as observed in the plots of observed against predicted values (Fig. 1a-c). Moreover, $95 \%$ of the future predictions would deviate, with a probability of $95 \%$, by less than $20 \%$ from the true value for the birch, by less than $15 \%$ for the oak, and by no more than $10 \%$ for radiata pine (Table 4). Model M3, on the other hand, provided a good description of the mortality trends for the Scots pine plantations dataset, as indicated by the goodness-of-fit estimates (Table 3). However, the error predictions for this species exhibited lower precision, with errors of up to $35 \%$ for $95 \%$ of the future predictions with $95 \%$ probability (Table 4, Fig. 1d). Mean absolute and relative biases did not differ significantly from zero for any of the species or mortality models examined (Table 3 ). The simultaneous $F$ test for slope equals one and zero intercept of the linear regressions of observed against predicted stand densities for the selected mortality models revealed that the regression parameters were not significantly different from the test values (Fig. 1).

Table 3 Goodness of fit of the mortality rate models examined

\begin{tabular}{|c|c|c|c|c|c|}
\hline \multirow{2}{*}{$\begin{array}{l}\text { Tree } \\
\text { species }\end{array}$} & \multirow[t]{2}{*}{ Model } & \multicolumn{4}{|c|}{ Model fit } \\
\hline & & $R^{2}$ adj & $\begin{array}{l}\text { RMSE } \\
\left.\left(\text { trees }^{-1}\right)^{-1}\right)\end{array}$ & $\begin{array}{l}\text { Absolute bias } \\
\left(\text { trees } \mathrm{ha}^{-1}\right)^{\mathrm{a}}\end{array}$ & $\begin{array}{l}\text { Relative } \\
\text { bias (\%) }\end{array}$ \\
\hline \multirow[t]{4}{*}{ Downy birch } & M1 & 0.958 & 138 & -2.5 & -0.12 \\
\hline & M2 & 0.914 & 199 & -29.5 & -3.44 \\
\hline & M3 & 0.966 & 125 & -2.9 & -0.03 \\
\hline & M4 & 0.968 & 121 & -2.4 & 0.04 \\
\hline \multirow[t]{4}{*}{ English oak } & M1 & 0.968 & 48 & -0.1 & 0.33 \\
\hline & M2 & 0.963 & 51 & -2.6 & -0.19 \\
\hline & M3 & 0.971 & 45 & -0.3 & 0.25 \\
\hline & M4 & 0.972 & 44 & -0.4 & 0.19 \\
\hline \multirow[t]{3}{*}{ Radiata pine } & M1 & 0.974 & 59 & 0.5 & 0.29 \\
\hline & M3 & 0.980 & 52 & 0.1 & 0.20 \\
\hline & M4 & 0.983 & 47 & -0.2 & 0.13 \\
\hline \multirow[t]{4}{*}{ Scots pine } & M1 & 0.888 & 437 & 8.1 & 2.08 \\
\hline & M2 & 0.866 & 479 & -23.1 & -1.36 \\
\hline & M3 & 0.899 & 415 & 10.6 & 1.68 \\
\hline & M4 & 0.887 & 439 & 12.4 & 1.09 \\
\hline
\end{tabular}

${ }^{\mathbf{a}}$ The absolute and relative biases for all regression models and tree species are not significantly different from zero

\section{Discussion}

Two of the four mortality models tested in this study (M2 and M4) have inflection points and predict reverse sigmoid pattern, while the other two describe a reverse Jshaped trend. The mortality patterns of three of the examined datasets were accurately described by reverse sigmoid curves predicted by model M4 (Fig. 2a-c), but they were also closely estimated by the reverse J-shaped curve, modeled by M3 (Table 3). Estimation of the mortality trend of the Scots pine plantations data by the reverse J-shaped model M3 was a logical outcome, considering the specific aspects of the modeled variable of these stands. Scots pine plantations in Bulgaria are characterized by a wide range of predominantly high stand densities, which implies a short initial growth phase followed by a steep gradient of the survival curve (Fig. 2d). Sets of polymorphic curves with multiple asymptotes were generated to represent the mortality process for all stand types, which was achieved by specifying a site specific parameter $\left(c_{0}\right)$ in the exponent.

Álvarez-González et al. (2004) generalized that most standlevel mortality rate models are derived from three differential equations that differ in the way they express the relative rate of change in the number of trees: proportional to power, hyperbolic, or exponential function of age. Previous studies on the density decrease pattern of the Scots pine plantations, downy birch and English oak natural stands from northwest Spain derived mortality rate functions based on the power-form differential equation (Diéguez-Aranda et al. 2005b; GómezGarcía 2011), while the mortality model developed for radiata pine plantations in the same region is based on the exponential form differential equation (Álvarez-González et al. 2004). In the present study, we also examined several formulations for each of the three instantaneous mortality rate models, by considering the dominant stand height, instead of age, as a predictor variable. The models derived from the hyperbolic form differential equation did not produce functional relationships of logical behavior, while the models based on the exponential form differential equation produced estimates for the base parameter less than 1 , which violates a requirement for derivation of the integral equation form (Diéguez-Aranda et al. 2005b). Models M1 and M2 developed in the present study are mortality rate functions based on the power form differential equation by considering specific constant values for the global model parameters:

$$
\begin{aligned}
& \text { M1 }: \frac{\Delta N / \Delta H}{N}=N^{-1} \gamma H^{\delta}, \delta=-b_{1}-1, \gamma=-b_{1} c_{0} \\
& \text { M2 }: \frac{\Delta N / \Delta H}{N}=N \gamma H, \gamma=-2 c_{0}
\end{aligned}
$$

Both models, particularly model M1, provided very good fits for the datasets examined, which confirmed the already 

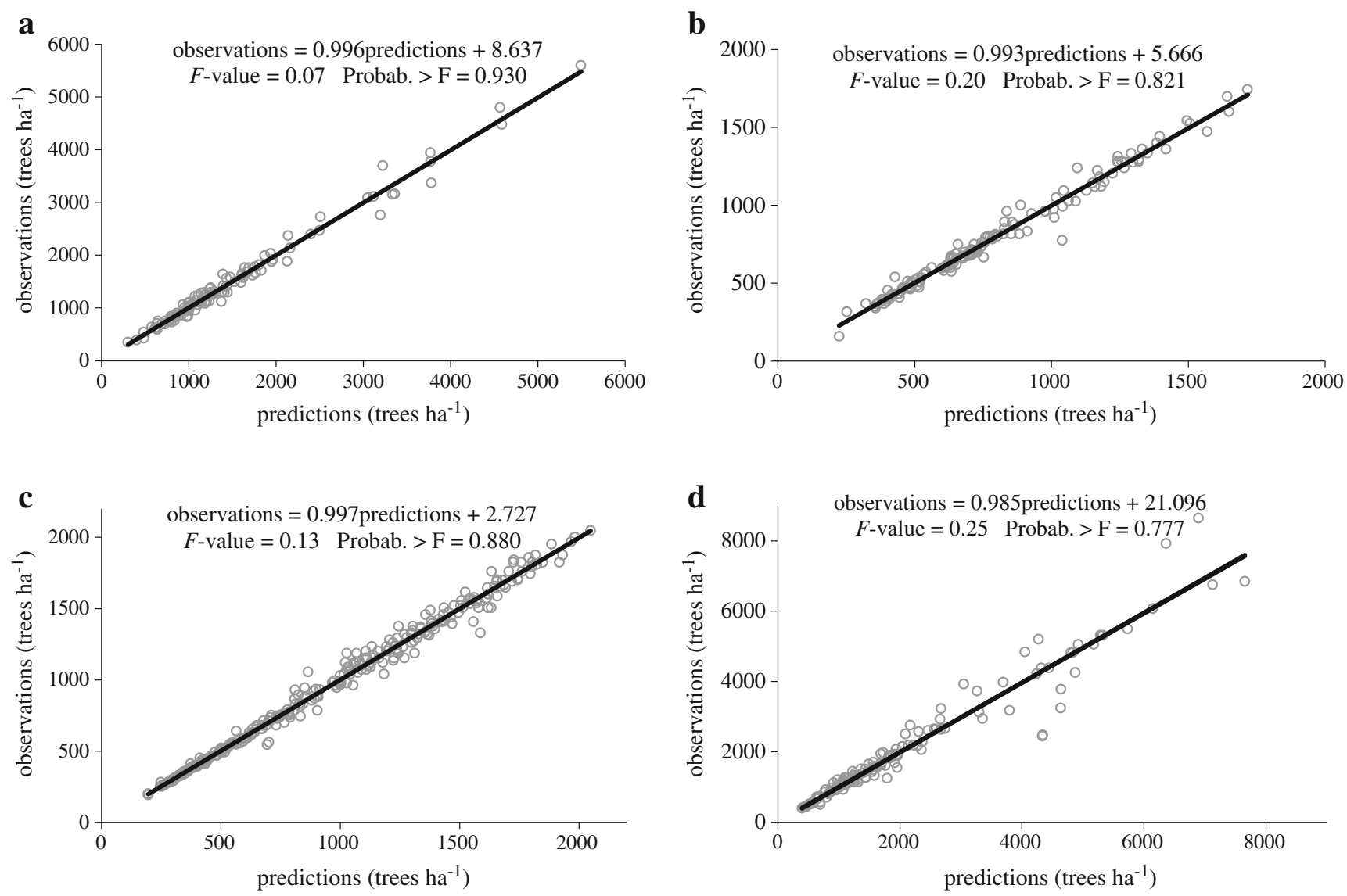

Fig. 1 Plot of observed against predicted values for the fitted mortality models. a Downy birch stands, b English oak stands, c Radiata pine plantations, and $\mathbf{d}$ Scots pine plantations. Linear regressions of observed

against predicted stand density are fitted and the results from simultaneous $F$ test for line slope equals 1 and zero intercept (Gadow and Hui 1999) are shown in the plots

manifested advantage of the functional forms of this type in modeling the density decrease pattern of the even-aged stands in the study region. Models M3 and M4 cannot

be assigned to any of the three groups stand-level mortality rate models and represent a new and better alternative for describing the regular stand mortality.

Table 4 Error estimates and significance of the selected mortality models

Tree species/mortality model Regression estimation

Error intervals ${ }^{\mathrm{a}, \mathrm{b}}$

Global parameter estimate Standard error $T$ value Confidence interval Prediction interval Tolerance interval

\begin{tabular}{|c|c|c|c|c|c|c|c|c|c|c|}
\hline \multirow[t]{2}{*}{ Downy birch/M4 } & $b_{1}$ & 3,891 & 434.3 & $8.96^{*}$ & -26 & 21 & -245 & 241 & -274 & 269 \\
\hline & & & & & -1.4 & 1.5 & -15.1 & 15.2 & -16.8 & 16.9 \\
\hline \multirow[t]{2}{*}{ English oak/M4 } & $b_{1}$ & 4,835 & 1,036 & $4.67 *$ & -8 & 7 & -89 & 88 & -97 & 96 \\
\hline & & & & & -1.1 & 1.2 & -13.5 & 13.6 & -15.0 & 15.0 \\
\hline \multirow[t]{2}{*}{ Radiata pine/M4 } & $b_{1}$ & 10,961 & 939.6 & $11.67 *$ & -5 & 5 & -94 & 93 & -100 & 99 \\
\hline & & & & & -0.4 & 0.7 & -9.1 & 9.4 & -9.7 & 10.0 \\
\hline \multirow[t]{2}{*}{ Scots pine/M3 } & $b_{1}$ & 112.3 & 24.19 & $4.64 *$ & -74 & 73 & -837 & 836 & -924 & 924 \\
\hline & & & & & -2.5 & 2.7 & -29.8 & 30.0 & -32.9 & 33.1 \\
\hline
\end{tabular}

${ }^{\mathbf{a}}$ The absolute errors (tree per hectare) are included in the first row, and the relative errors (\%) are shown in the second row in italics

${ }^{\mathbf{b}}$ The relative errors of the English oak and both the relative and absolute errors of the Scots pine showed deviations from the normal distribution. Consequently, $10 \%$ trimmed means and jackknife standard deviations were used for estimation of the error intervals in these cases (Rauscher 1986)

* Significant at $P<0.001$. 

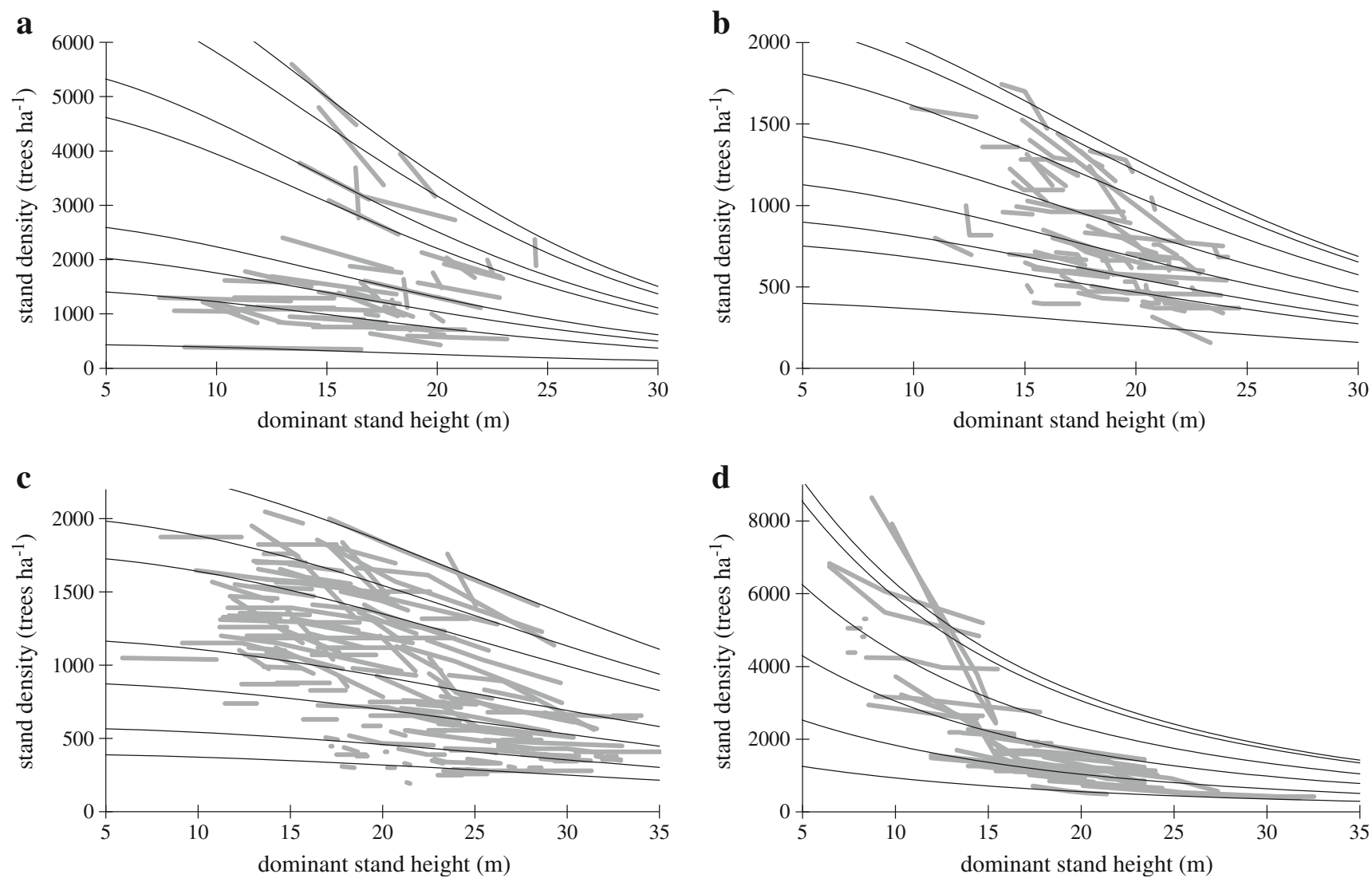

Fig. 2 Mortality models fitted to the experimental data. a Downy birch stands, b. English oak stands, c Radiata pine plantations, d Scots pine plantations. A subset of six to eight fitted curves comprising the density range for each of the species is shown

Stand-level rate mortality models are generally criticized for being imprecise and of low predictive ability due to the high variability in the survival patterns among different stands of the same age and tree species. In a similar way to earlier mortality-rate models, which include the site index (in addition to age) as an explanatory variable (Álvarez-González et al. 2004; Diéguez-Aranda et al. 2005b), we attempted to overcome the problem in two ways. The mortality rate models proposed here are functions of stand height, which is generally accepted as a spatial growth characteristic. However, the stand dominant height can also be viewed as a more complex indicator of the stand growth stage. Stand age, which is the growth stage variable most commonly applied, does not provide information about the site conditions that determine plant growth. Stand dominant height, on the other hand, as a characteristic of the growth stage reflects the interaction between age and site conditions, i.e., a given growth stage (dominant height) is reached at different ages, depending on the site conditions. Thus, the site quality, as a site specific factor, is intrinsically indirectly incorporated in mortality models based on the dominant stand height. These models, on the other hand, are fitted in algebraic difference equation form, which allows one of the equation parameters to vary between stands of the same type, i.e., it provides an additional dimension to capture the variability due to differing environmental and genetic factors.

The stand-level mortality models proposed here involve a one-step procedure for estimating the reduction in tree number at stand level. Combination with the probabilistic approach in two- and three-step modeling algorithms might be considered in the future, to better address the different time of onset of the self-thinning process. However, it should be pointed out that use of the one-step mortality rate model is the only approach that directly guarantees the path-invariance property of the mortality curve, and this is recommended as the best model for inclusion in a stand-level simulator (Diéguez-Aranda et al. 2005b).

While dynamic SDMDs consider either a density-decrease model (Castedo-Dorado et al. 2009; Newton 2012a, b) or a size-density model (Shibuya et al. 1997; Stankova and Shibuya 2007) for stand growth projection, two-component systems composed of both density-decrease and size-density models have also been developed in dynamic growth modeling. These composite systems involve a two-step application procedure consisting of projecting the stand density to a future point in time through a dynamic mortality rate model and subsequently substituting the estimated value into a size-density relationship, 
which expresses the growth of some tree size variable (average tree diameter, biomass, or stem volume) as a function of stand density (Smith and Hann 1986; Puetmann et al. 1993; Cao et al. 2000). Implementation of the density decrease models developed in the present study as submodels of such twocomponent growth systems within the framework of a dynamic SDMD is one of the ways envisaged for their application. Simplicity of the submodels of such composite systems is a desirable property that we have also pursued in deriving the mortality models. Similarly, simplified forms of the density decrease models, which include only one sitespecific parameter and omit the site index as a predictor variable, have been implemented for radiata pine plantations, downy birch and English oak natural stands within the frame of whole-stand dynamic models (Castedo-Dorado et al. 2007; Gómez-García 2011).

Turnblom and Burk (2000) speculated that the system of density-decrease and size-density models should be formulated in such a way that the mutual dependence of mean size and density must be considered in both equations. Cieszewski and Bella (1993) recognized the influence of stocking on stand height growth and developed a density dependent height growth model for lodgepole pine, which included (in addition to age) a crowding index, determined according to Czarnowski's stand dynamics theory, as a predictor. In line with the statement by Turnblom and Burk (2000) that growth and mortality are interrelated and bounded by the maximum density-mean size line, Czarnowski's stand dynamics theory defines a crowding index for fully stocked stands as the product of the squared dominant height and density that remains constant during the stand life (Cieszewski and Bella 1993). The concept of the growth-density interdependence is accounted for in the net density change function included in the dynamic SDMD developed by Newton (2012a, b). The model allows for bidirectional dependence by inclusion of two variables, the minimum asymptotic density at which density dependence initiates, and the relative density index, which are estimated through functions of the current mean stem volume and the maximum attainable (asymptotic) stand density, or the mean stem volume alone. The present research offers different view of the size-density interdependence. The stand dominant height, which was chosen instead of age to indicate the growth stage, is also a commonly used measure of the stand growth potential characterized by dominant height at a reference age (site index). Thus, the reduction in the tree number described by the dominant height-dependent mortality equations reflects not only the period of time from stand establishment, but also the potential of the trees to grow and compete according to the specific genetic and environmental factors.

One of the most important applications of SDMDs is to plan density-regulating thinning activities according to preferred management objectives. Regardless of the way in which the newly derived mortality models are applied (alone or within a dynamic whole-stand model) and regardless of the form of their inclusion within the SDMD framework (directly or as an element of a two-component system), they will be particularly useful for planning thinning activities according to the relative spacing index. The relative spacing (Hart-Becking) index, which is defined by the average distance between the trees, expressed as a proportion of dominant stand height, can be easily estimated from any projected pair of values of dominant stand height and number of trees, when the currently derived density decrease models are applied. Thus, the time of thinning and the between-thinning intervals can be designed according to prespecified values of the relative spacing index. In case of constructed limits for the relative spacing index, which yield maximum and minimum number of trees for any particular stand height, a range of thinning intensities can be defined, thus avoiding undesirable crowding and stand instability.

\section{Conclusions}

The dominant height-dependent mortality equations developed in the present study provide a simple and reliable approach to modeling the regular trends in density decrease for even-aged natural stands and plantations. The models can be considered for direct incorporation within the framework of a dynamic stand-level model (e.g., a dynamic SDMD) or as a submodel of two-component dynamic growth system composed of density-decrease and size-density relationships. In addition to projecting the tree number with the stand dominant height growth, they will be particularly useful for planning the time, frequency, and intensity of the thinning activities according to the relative spacing index.

Acknowledgments We are grateful to the Forest Research Institute of the Bulgarian Academy of Sciences and to Professor I. Marinov, who granted some of the data from Scots pine plantations used in this study. We also thank Dr F. Castedo-Dorado, who provided the radiata pine dataset (obtained in studies funded by the Spanish Ministry of Education and Science through project no AGL2004-07976-C02-01, co-financed with ERDF) and offered valuable advice on preparation of the manuscript. Collection of the birch and oak data was financed by the Spanish Ministry of Education and Science, through project no AGL2007-66739-C02-01, co-financed with ERDF, of which Dr U. Diéguez-Aranda was the team leader. We also express our gratitude to the editors and the anonymous reviewers for their critical suggestions and recommendations, which helped us to improve an earlier version of the manuscript.

Funding This work was financially supported by the Marie Curie IntraEuropean Fellowship Project within the 7th European Community Framework Programme: "Elaboration of advanced-level models for density management of coniferous and broadleaved even-aged natural stands and plantations in Europe" (PIEF-GA-2009-235039), conducted at the University of Santiago de Compostela, Spain. 


\section{References}

Adame P, del Río M, Cañellas (2010) Modeling individual-tree mortality in Pyrenean oak (Quercus pyrenaica Willd.) stands. Ann For Sci 67:810. doi:10.1051/forest/2010046

Álvarez-González JG, Castedo-Dorado F, Ruiz González AD, López Sánchez CA, von Gadow K (2004) A two-step mortality model for even-aged stands of Pinus radiata D. Don in Galicia (Northwestern Spain). Ann For Sci 61:439-448. doi:10.1051/ forest:2004037

Álvarez-González JG, Zingg A, Kv G (2010) Estimating growth in beech forests: a study based on long term experiments in Switzerland. Ann For Sci 67:307. doi:10.1051/forest/2009113

Andrews WK (1989) Heteroskedasticity and autocorrelation consistent covariance matrix estimation. Cowles Foundation Discussion Paper 887R. Cowles Foundation for research in economics at Yale University, New Haven, CT, USA

Cao QV, Dean TJ, Baldwin VC (2000) Modeling the size-density relationship in direct-seeded Slash pine stands. For Sci 46:317321

Castedo-Dorado F, Diéguez-Aranda U, Álvarez-González JG (2007) A growth model for Pinus radiata D. Don. stands in north-western Spain. Ann For Sci 64:453-465

Castedo-Dorado F, Crecente-Campo F, Álvarez-Álvarez P, Barrio-Anta M (2009) Development of a stand density management diagram for radiata pine stands including assessment of stand stability. Forestry 82:1-16. doi:10.1093/forestry/cpm032

Cieszewski CJ (2003) Developing a well-behaved dynamic site equation using a modified Hossfeld IV function $Y^{3}=\left(\mathrm{ax}^{\mathrm{m}}\right) /\left(c+x^{\mathrm{m}-1}\right)$, a simplified mixed-model and scant subalpine fir data. For Sci 49:539-554

Cieszewski CJ, Bella LE (1993) Modelling density-related lodgepole pine height growth, using Czarnowski's stand dynamics theory. Can J For Res 23:2499-2506

Cieszewski CJ, Harrison M and Martin SW (2000) Practical methods for estimating non-biased parameters in self-referencing growth and yield models. University of Georgia PMRC-TR 2000-7

Clutter JL, Fortson JC, Pienaar LV, Brister GH, Bailey RL (1983) Timber management: a quantitative approach. Wiley, New York, NY

Collet C, Le Moguedec G (2007) Individual seedling mortality as a function of size, growth and competition in naturally regenerated beech seedlings. Forestry 80:359-370

Crecente-Campo F, Soares P, Tomé M, Diéguez-Aranda U (2010) Modelling annual individual-tree growth and mortality of Scots pine with data obtained at irregular measurement intervals and containing missing observations. For Ecol Manage 260:1965-1974

Diéguez-Aranda U, Burkhart HE, Rodríguez-Soalleiro R (2005a) Modeling dominant height growth of radiata pine (Pinus radiata D. Don) plantations in north-western Spain. For Ecol Manage 215:271-284

Diéguez-Aranda U, Castedo-Dorado F, Alvarez-Gonzalez JG, Rodriguez-Soalleiro R (2005b) Modelling mortality of Scots pine (Pinus sylvestris L.) plantations in the northwest of Spain. Eur J Forest Res 124:143-153. doi:10.1007/s10342-004-0043-5

Eid T, Øyen BH (2003) Models for prediction of mortality in evenaged forest. Scand J For Res 18:64-77

Fridman J, Ståhl G (2001) Three-step approach for modelling tree mortality in Swedish forests. Scand J For Res 16:455-466. doi:10.1080/02827580152632856

Gadow K, Hui G (1999) Modelling forest development. Kluwer, Dordreht, The Netherlands

García-Gonzalo J, Marques S, Borges JG, Botequim B, Oliveira MM, Tomé J, Tomé M (2011) A three-step approach to post-fire mortality modelling in maritime pine (Pinus pinaster Ait) stands for enhanced forest planning in Portugal. Forestry 84:197-206. doi:10.1093/forestry/cpr006
Gómez-García E (2011) Modelos dinámicos de crecimiento para rodales regulares de Betula pubescens Ehrh. y Quercus robur L. en Galicia. PhD thesis, Universidade de Santiago de Compostela, Spain

Gregoire TG (1987) Generalized error structure for forestry yield models. For Sci 33:423-444

Gregoire TG, Schabenberger O, Barrett JP (1995) Linear modelling of irregularly spaced, unbalanced, longitudinal data from permanentplot measurements. Can J For Res 25:137-156

Hagihara A (1998) A practical model for the time-trajectory of mean phytomass and density in the development of even-aged pure stands. J For Plann 4:65-69

Hagihara A (2000) Time-trajectory of mean plant mass and density. Bull Fac Sci Univ Ryukyus 70:99-112

Hawkes C (2000) Woody plant mortality algorithms: description, problems and progress. Ecol Model 126:225-248

Krastanov K, Belyakov P, Shikov K (1980) Dependencies in the structure, growth and productivity of the Scots pine plantations and thinning activities in them. Research report. For Res Inst of BAS, Sofia (in Bulgarian)

Marinov I (2008) Investigation and evaluation of erosion in some regions of South-western Bulgaria. DSci thesis, For Res Inst of BAS, Sofia, Bulgaria (in Bulgarian)

Newton P (2009) Stand density management diagrams. http://www. scitopics.com/Stand_Density_Management_Diagrams.html\#biblio. Accessed 3 Nov 2009

Newton PF (2012a) A silvicultural decision-support algorithm for density regulation within peatland black spruce stands. Comput Electron Agric 80:115-125. doi:10.1016/j.compag.2011.10.012

Newton PF (2012b) A decision-support system for forest density management within upland black spruce stand-types. Environ Model Softw 35:171-187. doi:10.1016/j.envsoft.2012.02.019

Palahí M, Pukkala T, Miina J, Montero G (2003) Individual-tree growth and mortality models for Scots pine (Pinus sylvestris L.) in north-east Spain. Ann For Sci 60:1-10

Puetmann KJ, Hann DW, Hibbs DE (1993) Evaluation of the sizedensity relationships for pure red alder and Douglas-fir stands. For Sci 39:7-27

Rennolls K, Peace A (1986) Flow models of mortality and yield for unthinned forest stands. Forestry 59:47-58. doi:10.1093/forestry/ 59.1 .47

Rauscher HM (1986) The microcomputer scientific software series 4: testing prediction accuracy. US For Serv Gen Tech Rep NC-107

Shibuya M (1995) A simple and practical model for mean size-density trajectories of tree stands. J Jpn For Soc 77:247-253

Shibuya M, Yajima T, Matsuda K (1997) A modified stand density control diagram for Japanese white birch based on a trend of mean volume-density relationships with stand growth. Res Bull Hokkaido Univ For 54:202-211

Smith NJ, Hann DW (1986) A growth model based on the selfthinning rule. Can J For Res 16:330-334

Stankova T, Shibuya M (2007) Stand density control diagrams for Scots pine and Austrian black pine plantations in Bulgaria. New Forests 34:123-141

Stankova T, Stankov H, Shibuya M (2006) Mean-dominant height relationships for Scotch pine and Austrian black pine plantations Bulgaria. Ecol Engin Envir Protect 2:59-66

Turnblom EC, Burk TE (2000) Modeling self-thinning of unthinned Lake States red pine stands using nonlinear simultaneous differential equations. Can J For Res 30:1410-1418

Woodall CW, Grambsch PL, Thomas W (2005) Applying survival analysis to a large-scale forest inventory for assessment of tree mortality in Minnesota. Ecol Model 189:199-208. doi:10.1016/ j.ecolmodel.2005.04.011

Woollons RC (1998) Even-aged stand mortality estimation through a two-step regression process. For Ecol Manage 105:189-195 